\title{
What is "sanology" and is she needed?
}

Apanasenko G.L

Department of physical and rehabilitation medicine of the National medical academy of postgraduate education the name of P.L. Shupiк, Kyiv, Ukraine

Corresponding Author: Apanasenko G.L. Department of physical and rehabilitation medicine of the National medical academy of postgraduate education the name of P.L. Shupiк, Kyiv, Ukraine.

Received date: April 01, 2021; Accepted date: April 27, 2021; Published date: April 30, 2021

Citation: Apanasenko G.L. (2021) What Is "Sanology" And Is She Needed? .Clinical Research and Clinical Trials. 3(3); DOI: 10.31579/26934779/033

Copyright: () 2021 Apanasenko G.L, This is an open access article distributed under the Creative Commons Attribution License, which permits unrestricted use, distribution, and reproduction in any medium, provided the original work is properly cited.

\begin{abstract}
The necessity of the use of term of «санология» comes into question for denotation of the научнопрактического direction related to the «management by the health» of individual: monitoring of health level, setting of health measures, their realization, estimation of efficiency. Aim: achievement of «safe health level».
\end{abstract}

Keywords: санология; prophylaxis of chronic uninfectious diseases; «safe health level»

\section{Introduction}

How to name the area of the knowledge and practical methods, sent to maintenance, strengthening and renewal of health practically healthy man, but without the use of the sophisticated diagnostic apparatus, medications or surgical interferences? Medicine? Hardly. A word «medicine» originates from the Latin word-combination of ars medicine («curative art», «art healing) and has the same root, what verb of «medeor» (I cure). Obviously, that without medications and trade of surgeon medicine not to cost. It can be "paramedicine"? That is Wikipedia determines: paramedicine is an area of complementary medicine, including the various pseudo-scientific methods of treatment. Or: Division of medicine, studying the methods of providing of urgent medical or medicare on the prehospital stage. No, in our case speech goes about the fully material and well-proven methods (not at all pseudoscientific!) of decision of problems of health. The question is about the complex of measures, that does not allow to the healthy man to go across a verge illness begins after that. Id est to appearance of the state that requires intervention from a doctor. It is needed to search other term. And, probably, most a suitable term will be "sanology". Under sanology it is necessary to understand direction, the article of research of that is an individual health, his mechanisms and management possibilities by these mechanisms. Presently there is only one country, where practical speciality of doctor-sanology (doctor on a health) is ratified, qualifying description is prepared and systematic preparation of specialists comes true. It is Ukraine.

\section{Why was this problem?}

And a problem arose up because quite new direction [1, 2], accountable for the maintenance and strengthening of health of man, related to the necessity of realization of new strategy of prophylaxis of chronic uninfectious diseases (CUD), is now formed. And it is not laid in the scopes of the existent Orthodox ideas about that, where corresponding measures must be conducted, by whom and on what basis. A healthy man Auctores Publishing - Volume 3(2)-033 www. auctoresonline.org uninteresting a doctor, because he cannot show all power of the intellect and professionalism. But someone must occupy practically by healthy people that they did not pass to the category of patients. If for the state of patient a doctor bears the responsibility, being the representative of powerful social structure, then for the state practically of healthy people nobody is responsible, as be not structure accountable for it. Reasons our contemporary mainly dies from that, it is illnesses of way of life (IHD, cerebral stroke, diabetes, etc.). Quite obviously, that to the social institute that carries the name health «protection», the function of forming of way of life is not inherent. He is forced to engage in the violators of his principles.

In connection with that development of CUD takes place very gradually, and the Orthodox methods of medicine are not able to define a transition border from a health to illness, new methodology and methodical approaches of decision of this problem are needed. They are worked out by us and have world priority [3]. And main - sharply the scales of involving of population increase for participating in these measures. Practically healthy everybody must be engaged in them. The known health centre system conducted in a medical department trying to overcome clinical inspections all population well, failed for many reasons (costliness, small efficiency, etc.). The most important difference of new direction from existent approaches is taking away of measures on warning of development of CUD outside a medical department, simplicity of methodical receptions and their availability for persons not having medical education, realization of unmedicamental health measures outside curative establishments. Thus not denied NECESSITY realizations of «aiming» clinical examinations (age-related or regional risk of development of diseases).

\section{What does it give?}

-increase of efficiency of prophylactic measures due to more early them назначения-до of beginning of forming of disease

-fall-off of their cost; 
-the department of health protection will be released from the inefficient spending of facilities and distraction of shots from curative work of and other

Theoretical bases and maintenance of new direction of prophylaxis of CUD

New direction of prophylaxis of CUD ideas are the basis of that human organism it is the open thermodynamics system stability of that is determined by her energypotential. An external display of potential of energy of the living system is maximal aerobic ability, reflecting efficiency of function of mitohondries. By us the phenomenon of «safe health level» [4] that is the aim of the conducted health measures is first described, and an exit of individual outside a «safe zone» is a signal requiring active measures. (Presently such signal is manifestation of pathology process or presence of endogenous risk factors). Essence of these measures- management by the health of individual, id est monitoring of health level (amounts) and setting of health methods to beginning of manifestation of disease with the purpose of achievement of «safe» level of health («preventive rehabilitation»). The worked out methodology and methodology of estimation of health level allow to distinguish from general mass practically the healthy people of risk group and to appoint the individual program of making healthy to them [1]. Methodology of expressestimation of health level is accessible for persons without medical education, is cheap, does not require a difficult equipment. Among health measures, educating of population to bases of health, methods of self-control of the state, health physical training of mainly aerobic orientation, rationalization of feed, hardening, simplest methods of psyhostands on the first place. Every individual must pass the stages: I know, I want, I am able, I do.

\section{Organization of new direction of prophylaxis of CUD}

In basis of realization of new direction are state and private structures. Probably, there must be an administrative agency accountable for this direction. The most suitable variant is creation in every region of department of health with a corresponding infrastructure and vertical management line. Large army of specialists on a fitness, physical rehabilitation and doctors on sport will be skilled basis of this organization. From private forms, taking part in the decision of problem is a network of fitnes, private health clubs etc. A large role public organizations and funds, able to stimulate the organs of local selfgovernment on business of organization of athletic-health work with a population, can play.

Researches show that within the limits of «safe zone» of health is only $1 \%$ population of Ukraine, id est for the bulk of the Ukrainian population realization of systematic health measures is required. Medicine is here powerless: her methods influence on the mechanisms of illness and unable to fix a health. Only realization of principles of sanology can decide the problem of health of population.

\section{References}

1. Apanasenko GL .(2019)The epidemic of chronic noninfectious diseases: new conception of prophylaxis.- Nursing \& Healthcare International Journal, ,3(4), 198

2. Apanasenko G.L. (2019) LAWS OF THERMODYNAMICS and public health. Archives of nutrition and public health , v.1, issue 2, 5 okt

3. Apanasenko G.L. (2014) Epidemic of chronic uninfectious diseases: strategy of survival. Saarbrukken: Lambert Acad. Publ; 260

4. Апанасенко Г. Л. (1992) Evolution of bioenergetics and health of man. Saint Petersburg, Petropolis, 137 p. 